Pawlicki Mateusz, Lopuszyńska Anna, Kozioł Magdalena, Krasa Aleksandra, Piekarska Ewa, Piecewicz-Szczęsna Halina. Sleep disorders in patients with neoplasm. Journal of Education, Health and Sport. 2020;10(9):514-519. eISSN 2391-8306. DOI http://dx.doi.org/10.12775/JEHS.2020.10.09.062

https://apcz.umk.pl/czasopisma/index.php/JEHS/article/view/JEHS.2020.10.09.062 https://zenodo.org/record/4042199

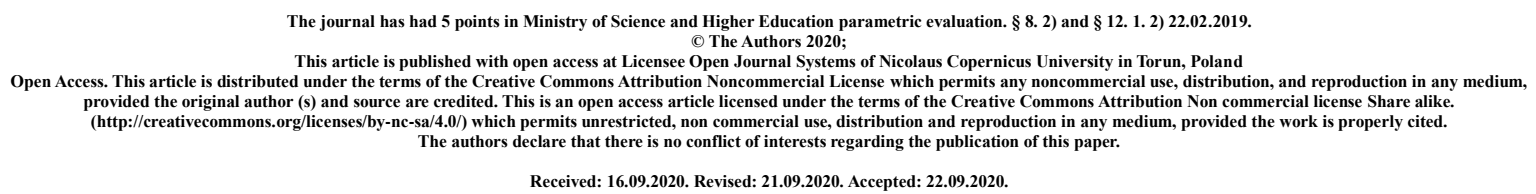

\title{
Sleep disorders in patients with neoplasm
}

\author{
Mateusz Pawlicki ${ }^{1}$, Anna Lopuszyńska ${ }^{1}$, Magdalena Koziol ${ }^{1}$, Aleksandra Krasa ${ }^{1}$, \\ Ewa Piekarska ${ }^{1}$, Halina Piecewicz-Szczęsna ${ }^{2}$
}

${ }^{1}$ Student Scientific Association at Department of Epidemiology and Clinical Research Methodology Medical University of Lublin, ul. Radziwiłłowska 11, Lublin 20-080, Poland

${ }^{2}$ Department of Epidemiology and Clinical Research Methodology of the Medical University of Lublin, ul. Radziwiłłowska 11, Lublin 20-080, Poland

Corresponding author: Mateusz Pawlicki, pawlak32@gmail.com

ORCID ID:

Mateusz Pawlicki https//orcid.org/0000-0001-8318-6573, pawlak32@ gmail.com Anna Łopuszyńska https://orcid.org/0000-0001-5133-4180, lopuszynskaania@gmail.com Magdalena Kozioł https://orcid.org/0000-0002-8671-5968, magdalena.koziol@icloud.com Aleksandra Krasa https://orcid.org/0000-0002-0733-202X, ola.AK62@gmail.com Ewa Piekarska https://orcid.org/0000-0002-4954-379X; piekarskaewaa@gmail.com 


\begin{abstract}
:
Introduction: Sleep disorders are a big group of disturbances affecting many people in the world. They can appear as insomnia, interrupted sleep, worsened sleep quality or trouble falling asleep. Although they may not seem very dangerous, they lead to various unpleasant complications and even diseases. Cancer is said to be one of the possible sources of the problem.
\end{abstract}

Results: Studies show relationship between cancer and sleep disruptions. They are frequent in lung, head and neck, gynecologic and breast neoplasms. Patients report higher scores of Pittsburgh Sleep Quality Index, insomnia severity scale and Epworth Sleepiness Scale meaning that they can be considered as poor sleepers. In addition, they often develop psychiatric disorders which are linked with higher risk of sleep problems.

Conclusions: According to many research, cancer often comes with somnipathies. It should be taken into consideration when planning oncologic treatment and care to obtain the best effects of the therapy.

Key words: cancer, neoplasm, sleep, insomnia, sleep disorders

\title{
Introduction:
}

Sleep as one of the basic human needs plays a crucial role in maintaining homeostasis. It is important not only for our nervous system but also for the proper work of immune, cardiovascular and hormone systems [1]. It is also a major factor in correct growth and development of children and adolescents [2]. A healthy sleep can be characterized with a few factors: duration, quality, timing, regularity and occurrence of disturbances [3]. If any of them is impaired, sleep disorders appear. Sleep disorders (somnipathies) create a large group of various disruptions. They can be divided using three different classifications: International Classification of Diseases (ICD-9-CM and ICD-10-CM), Diagnostic and Statistical Manual of Mental Disorders (DSM) and The International Classification of Sleep Disorders (ICSD). However the third one is the most widely used. The first version was primarily published in 1979 and the latest, already third (ICSD-3), is from 2014. It allocates somnipathies in seven main categories:

- Insomnia

- $\quad$ Sleep-related breathing disorders

- Central disorders of hypersomnolence

- $\quad$ Circadian rhythm sleep-wake disorders

- $\quad$ Parasomnias

- $\quad$ Sleep-related movement disorders

- Others

Further they split into sixty different more precise diagnoses [4]. All of above may lead to significant problems such as worsened concentration, bad mood, anxiety or low energy and daytime sleepiness. It disturbs everyday functioning and, as a result, aggravates the quality of life. What is more, they enhance the risk of certain diseases: type 2 diabetes mellitus, hypertension or metabolic syndrome [5]. Even though sleep hygiene is important more and more people report having problems with it. 
Studies say that about $30 \%$ of population suffer from insomnia [6, 7]. However as much as $50,5 \%$ Polish adults reported subjective insomnia [8]. Risk factors are very diverse. Most common are older age, female gender, stress [9, 10], lifestyle, environment, medications [5] and other medical conditions, especially psychiatric ones $[6,11]$. Some studies also indicate correlations between somnipathies and neoplastic disorders. Importance of that information comes from both severity and epidemiology of these diseases. As one of the most dangerous and often hard to treat conditions, it is essential to maintain proper quality of life of the patients by coping with comorbidities. What is more their number constantly grows. In 2020 it is predicted that 1806590 people in the USA only will have their cancer diagnosed. At the same time 606520 people will die [12]. This clearly shows the sense of understanding the connection between sleep disorders and neoplasms.

\section{A review of available research:}

Cancer is a very unique type of disease. Due to its severity, it often affects not only one organ or system but strongly impacts whole organism impairing patients' functioning. They may report a number of diverse symptoms but the most frequent is pain. Afterwards come constitutional symptoms like weight loss, fever, fatigue and dyspnea [13, 14]. Oncologic patients are also very likely to develop mental health issues. Depression, anxiety or even post-traumatic stress symptoms are quite common even among survivors $[15,16,17]$. Complicated and exhausting treatment methods cannot be forgotten as well. As a result of all of these problems, many patients develop sleep disorders additionally influencing their hard situation.

In a study carried out by Jakobsen et al. forty patients with metastatic cancer using WHO step III opioids were examined using patient-recorded outcome results (Pittsburgh Sleep Quality Index) and polysomnography or actigraphy. The mean PSQI global score was 6,5 , mean sleep onset latency and mean total amount of time being awake during night according to patients' records were 46 minutes and 37 minutes respectively. Actigraphy results were 35 minutes for mean onset latency and 40 minutes for total amount of time awake during night. Mean number of awakenings was 24. It clearly shows that people with advanced cancer suffer from bad quality of sleep. Additional strength of that study was the usage of actigraphy which was able to evaluate data gathered from reports filled by patients being near the end their lives. That greatly helped reducing subjectivity of such methods [18].

Another study from Turkey assessed 1245 of lung cancer cases. Bülbül et al. asked if they "frequently have difficulty in falling asleep at night or waking up frequently during the night or getting back to sleep after waking during the night?". The results showed that $82,1 \%$ reported fatigue, $60,8 \%$ daytime sleepiness and $48,4 \%$ difficulties with initiating or maintaining sleep. The most common reasons were pain and dyspnea. Patients with insomnia constituted $44,7 \%$ of the group. What is interesting, $65,5 \%$ of them had depression and $71,4 \%$ anxiety. They also had higher rates of pain, dyspnea and nausea. Female sex, stage 3 or 4 disease, metastases and weight loss above $5 \mathrm{~kg}$ were combined with the higher risk of developing insomnia [19]. Subjects with lung cancer were examined by the Lou et al. as well. Among 128 patients with advanced lung cancer (stage III and IV), 62,5\% had sleep disturbances. $35,9 \%$ of patients described their sleep as fairly bad or very bad. 
The mean global PSQI global score was 7,81 with $62,5 \%$ scoring 5 or higher. Respiratory symptoms were linked with worse quality of sleep [20].

Some of cancer types are stronger linked with sleep disorders than other ones. According to Armstrong et al. insomnia is the most common sleep-wake disorders in patients with brain tumors [21] and Faiz et al. states that obstructive sleep apnea can be clinically confirmed in $84 \%$ of patients with head and neck tumors [22]. DelRosso et al. gathered 18 children with incidental pineal cysts (aged 6-12), 19 children with normal MRI and 100 ageand sex-related controls. Then they gave their parents the Sleep Disturbance Scale for Children to control their sleep quality. Kids with cysts had much higher scores of excessive sleepiness and disorders of initiating and maintaining sleep. What is more, the score corelated with the size of the cyst [23].

One of the strongest connections between cancer and sleep disorders described in literature can be seen in breast cancer. Overall they appear in 39,5\% to $69 \%$ of patients [24]. Carroll et al. enrolled 319 newly diagnosed female patients older than 60 and with any stage of the disease. At any point of the research (baseline, 12 months and 24 months) about one third of the patients reported problems with sleeping. Interestingly only 5,4\% of survivors reported them at all three points, $13 \%$ at two of three and $33 \%$ at only one. Treatment method did not influence the presence of sleep disorders [25]. In Tag Eldin's et al. study researchers compared the insomnia severity index (ISI) and Epworth Sleepiness Scale (ESS) of patients both genders after radiotherapy, chemotherapy and before any form of therapy. Before treatment $7,7 \%$ subjects scored $>14$ in ISI and 26,9\% scored $>11$ in ESS. The results after the therapy were $29,2 \%$ and $37,5 \%$ for chemotherapy and $4,2 \%$ and $25,0 \%$ after radiotherapy [26].

Sleep disturbances are also common in gynecologic cancers. According to Moran et al. $13,8 \%$ of women with diagnosed PCOS never have difficulties with sleeping. In comparison they are present in $17,3 \%$ of women without PCOS. However the answer "almost always" was chosen by $18,4 \%$ women with PCOS and only by $6,9 \%$ without. The study showed almost twice the odds of increased difficulty falling asleep compared with those without PCOS $(1,94)$. Higher BMI and depression tend to lower that effect [27]. Tien et al. showed the prevalence rates of poor sleep quality of $27,59 \%$ for female residents, $52,63 \%$ for women before adjuvant therapy and $64,50 \%$ for women after adjuvant therapy. Median PSQI scores altered as well: from 5,6 before therapy to 7,0 after [28].

\section{Conclusion:}

Sleep disorders are certainly linked with neoplastic diseases and can be seen as one of many of their symptoms. Due to their negative impact, they should be monitored to improve patients' quality of life. However since cancer diagnosis is often shocking for patient and may lead to issues with mental health, it is sometimes hard to differ the real source of the problem. The same applies to expensive and draining treatment methods. Because of that, we still need more research to better understand the problem and improve our care. 


\section{References:}

1. Watson NF, Badr MS, Belenky G, et al. Joint Consensus Statement of the American Academy of Sleep Medicine and Sleep Research Society on the recommended amount of sleep for a healthy adult: methodology and discussion. Sleep. 2015;38(8):1161-1183.

2. Owens JA, Weiss MR. Insufficient sleep in adolescents: causes and consequences. Minerva Pediatr. 2017;69(4):326-336. doi:10.23736/S0026-4946.17.04914-3

3. Watson NF, Badr MS, Belenky G, et al. Recommended Amount of Sleep for a Healthy Adult: A Joint Consensus Statement of the American Academy of Sleep Medicine and Sleep Research Society. Sleep. 2015;38(6):843-844. Published 2015 Jun 1. doi: $10.5665 /$ sleep. 4716

4. Sateia, MJ (2014). International classification of sleep disorders. Chest, 146(5), 13871394

5. Medic G, Wille M, Hemels ME (2017). Short-and long-term health consequences of sleep disruption. Nature and science of sleep, 9, 151.

6. Roth T (2007). Insomnia: definition, prevalence, etiology, and consequences. Journal of clinical sleep medicine, 3(5 suppl), S7-S10.

7. Bhaskar S, Hemavathy D, Prasad S (2016). Prevalence of chronic insomnia in adult patients and its correlation with medical comorbidities. Journal of family medicine and primary care, 5(4), 780.

8. Nowicki Z, et al. "Rozpowszechnienie subiektywnej bezsenności w populacji polskiej." Psychiatr Pol 50.1 (2016): 165-173.

9. Drake CL, Cheng P, Almeida DM, Roth T. Familial Risk for Insomnia Is Associated With Abnormal Cortisol Response to Stress. Sleep. 2017;40(10):zsx143. doi:10.1093/sleep/zsx143

10. Drake CL, Pillai V, Roth T. Stress and sleep reactivity: a prospective investigation of the stress-diathesis model of insomnia. Sleep. 2014;37(8):1295-1304. Published 2014 Aug 1. doi:10.5665/sleep.3916

11. Alvaro PK, Roberts RM, Harris JK. A Systematic Review Assessing Bidirectionality between Sleep Disturbances, Anxiety, and Depression. Sleep. 2013;36(7):1059-1068. Published 2013 Jul 1. doi:10.5665/sleep.2810

12. Siegel RL, Miller KD, Jemal A (2020), Cancer statistics, 2020. CA A Cancer J Clin, 70: 7-30. doi:10.3322/caac.21590

13. Donnelly S, Walsh D The symptoms of advanced cancer. Semin Oncol. 1995;22(2 Suppl 3):67-72.

14. Batalini F, Gomes M, Fábio I, Kuwae F, Macanhan G, Pereira JL. (2017). Cancer complaints: The profile of patients from the emergency department of a Brazilian oncology teaching hospital. F1000Research, 6 .

15. Carreira H, Williams R, Müller M, Harewood R, Stanway S, Bhaskaran K. Associations Between Breast Cancer Survivorship and Adverse Mental Health Outcomes: A Systematic Review [published correction appears in J Natl Cancer Inst. 2020 Jan 1;112(1):118]. J Natl Cancer Inst. 2018;110(12):1311-1327. doi:10.1093/jnci/djy177

16. Parker G, Brotchie H. Pancreatic Cancer and Depression: A Narrative Review. J Nerv Ment Dis. 2017;205(6):487-490. doi:10.1097/NMD.0000000000000593 
17. Yi JC, Syrjala KL. Anxiety and Depression in Cancer Survivors. Med Clin North Am. 2017;101(6):1099-1113. doi:10.1016/j.mcna.2017.06.005

18. Jakobsen G, Engstrøm M, Thronæs M, et al. Sleep quality in hospitalized patients with advanced cancer: an observational study using self-reports of sleep and actigraphy. Support Care Cancer. 2020;28(4):2015-2023. doi:10.1007/s00520-019-04998-5

19. Bülbül Y, Özlü T, Arınç S, et al. Sleep disturbances in patients with lung cancer in Turkey. Türkiye'de akciğer kanseri hastalarında uyku bozuklukları. Tuberk Toraks. 2018;66(4):297-303. doi:10.5578/tt.67689

20. Lou VW, Chen EJ, Jian H, et al. Respiratory Symptoms, Sleep, and Quality of Life in Patients With Advanced Lung Cancer. J Pain Symptom Manage. 2017;53(2):250-256.e1. doi:10.1016/j.jpainsymman.2016.09.006

21. Armstrong TS, Shade MY, Breton G, Gilbert MR, Mahajan A, Scheurer ME, Vera E, Berger AM (2016) Sleep-wake disturbance in patients with brain tumors. Neuro-Oncology 19(3):323-335.

22. Faiz SA, Balachandran D, Hessel AC, Lei X, Beadle BM, William WN Jr, Bashoura L (2014) Sleep-related breathing disorders in patients with tumors in the head and neck region. Oncologist 19(11):1200-1206.

23. DelRosso LM, Martin K, Bruni O, Ferri R. Sleep disorders in children with incidental pineal cyst on MRI: a pilot study. Sleep Med. 2018;48:127-130. doi:10.1016/j.sleep.2018.05.003

24. Chen D, Yin Z, Fang B. Measurements and status of sleep quality in patients with cancers. Support Care Cancer. 2018;26(2):405-414. doi:10.1007/s00520-017-3927-x

25. Carroll JE, Small BJ, Tometich DB, et al. Sleep disturbance and neurocognitive outcomes in older patients with breast cancer: Interaction with genotype. Cancer. 2019;125(24):4516-4524. doi:10.1002/cncr.32489

26. Tag Eldin ES, Younis SG, Aziz LMAE, Eldin AT, Erfan ST. Evaluation of sleep pattern disorders in breast cancer patients receiving adjuvant treatment (chemotherapy and/or radiotherapy) using polysomnography. J BUON. 2019;24(2):529-534.

27. Evans BJ, Phillips KM, Gonzalez BD, Apte S, Small BJ, Jacobsen PB, Jim HS (2016) Psychosocial resources and sleep disturbance before chemotherapy for gynecologic cancer. J Psychosoc Oncol 34(1-2):60-76.

28. Tian J, Chen GL, Zhang HR. Sleep status of cervical cancer patients and predictors of poor sleep quality during adjuvant therapy. Support Care Cancer 23, 1401-1408 (2015). 